\title{
Measurement of Adhesion Strength of Methane Hydrates to Wall
}

\author{
Alberto Di Lullo ${ }^{1 *}$, Pier Paolo Zonta ${ }^{2}$, Alberto Pontarollo ${ }^{2}$ and Sebastiano Correra ${ }^{1}$ \\ ${ }^{1}$ Eni SpA, Via Emilia, San Donato Milanese, Italy \\ ${ }^{2}$ Eni Progetti SpA, ANST, Via delle Industrie, Italy
}

Submission: January 10, 2018; Published: February 08, 2018

*Corresponding author: Lullo Alberto Giulio, Eni SpA, Via Emilia, San Donato Milanese, Milano MI, Italy, Email: Alberto.DiLullo@eni.com

\begin{abstract}
One of main risks in natural gas transport is formation of hydrate deposits in pipelines and sealines. In order to mitigate this problem, a possible solution could be to apply an appropriate inner coating, avoiding adhesion of hydrate particles to the pipe wall. With this purpose, different commercial coatings were characterized with traditional laboratory methods (roughness, water contact angle and diiodomethane contact angle) and performed adhesion force test with model hydrates (THF hydrates) at atmospheric pressure. Nevertheless, such measurement conditions are far from the real field conditions. Therefore, in order to assess the technology, a new experimental tool was developed to perform adhesion stress measurements on hydrocarbon hydrates under more representative operating conditions. The results of these measure- ments clearly show that the tests carried out with model systems at room pressure may provide misleading outcomes.
\end{abstract}

Keywords: Methane hydrate; Adhesion; Flow assurance; Coating

\section{Introduction}

Clathrate hydrates, or gas hydrates, are water-based solids physically resembling ice. Excellent review monographs on the subject are available [1,2]. The formation of hydrates in oil and/or gas transport sys- tem in presence of water, operating at sufficiently low tem- peratures and high pressures, can lead to complete ob- structions. Therefore, especially for subsea development, it is necessary to provide for storage, transportation and in- jection of additives to prevent hydrate formation.

In order to avoid the massive injection of chemicals, an appropriate internal coating could counteract adhesion of hydrate particles to the inner wall of pipe. While a large literature exists on the preparation and characterization of coated surfaces, very little / ambiguous information is available in the literature about hydrates adhesion is con-cerned. For this reason, different coatings were selected to investigate their ability to mitigate hydrate adhesion [3].

To assess the coatings performances two different tests were performed and compared:

A. an adhesion test with a model hydrate (water + THF)

B. an adhesion test with natural gas hydrates under representative conditions.

\section{Materials}

Experimental activity was focused on four different commercial coatings; their selection was based on data sheet provided by the manufacturers. Selected coatings belong to two types of polymers: Poly Tetra Fluoro Ethylene (PTFE) and Fluorinated Ethylene Propylene (FEP). In addition, a reference carbon steel substrate was investigated, in order to compare the results with respects to a bare material. Selected Polymeric Coatings are produced by two different manufacturers, hereinafter referred to as "A" and "B". Two A coatings and two B coatings were examined. Their color code make reference to the composition (Black and blue ones are PTFE based, while green ones are FEP based).

\section{Materials Characterization}

A preliminary surface characterization was carried out in terms of roughness and water and diiodomethane contact angle. These data was collected to investigate the possible correlation with the adhesion performances.

\section{Surface average roughness}

Measurement of roughness was performed by an optical 3D Microscope (Alicona Infinite Focus, Alicona Imaging GmbH, Raaba/Graz, Austria). This device combines the low depth of 
field of an optical microscope with vertical scanning, traversing across the surface of the sample, to provide high resolution and high depth of field topograph- ical images with a large field of view. Vertical resolution and lateral resolution are $10 \mathrm{~nm}$ and $400 \mathrm{~nm}$, respectively.

\section{Contact angle}

Hydrophobicity and oleophobicity of the surfaces were evaluated by means of the demineralized water contact an- gle (WCA) and Diiodomethane contact angle (DCA), re- spectively. Sessile drops for measurement were positioned on surfaces by means of a micro pipette (max. 20 $\mu \mathrm{l}$ ) and images of drops were taken by means of Nikon D90 equipped with macro objective (Nikon DX AF-S NIKKOR 18-105mm 1:3.5- 5.6G ED). Sample were positioned on a horizontal support. Collected pictures have been analyzed by means of the software Image J version 1.4.3.67 with a dedicated plug in: "Contact Angle version 0.2.0" levelled surface.

\section{Adhesion Test on Thf-Based System}

Room temperature adhesion measurements have been performed with a tool derived from the work of Smith et al. 3 After hydrate formation, a dynamometer (Sauter FK 100max $100 \mathrm{~N}$, precision $0,5 \% \mathrm{FSR}$ ), installed on a slide, pushed the cuvette to detach the hydrate from the substrate and record the peak force reached during the operation.

\section{Adhesion Test on Methane Hydrate}



A new system for methane hydrate adhesion measure- ments at representative conditions was designed and built based on the principle of a torsion shear test 21 . The appa-ratus, schematically described in Figure 1, is set up inside an autoclave to allow the formation of a methane hydrate adhesive layer between a fixed plate (sample surface) and the spring-driven head of the torque balance. As the hy- drate is formed the shaft is rotated and the angular posi- tion of the shaft at the hydrate detachment is recorded. This value gives a quantification of the force needed to re- move the hydrate from the surface. The comparison of measured values gives a rank of the materials with respect to hydrate adhesion. To avoid spurious hydrate detachment from the balance, the head surface was toothed to maximize adhesion.

The autoclave has been equipped with instruments and devices that allows to:

a. control the temperature imposed to the sample;

b. observe and acquire the methane hydrate formation on the sample by a video-endoscope located close the sample area;

c. Observe and acquire the measurements of the rotation during the torsion shear test by a video-endoscope located close the measurement area.

d. The value of shear stress is derived by means of the following equation

Where TTmmmmmm is the maximum tangential shear stress, $M$ is the measured torque, De the external diameter $(25 \mathrm{~mm})$ of the annulus and Di the inner diameter $(20 \mathrm{~mm})$ of the an- nulus.

\section{Result}

\section{Surface characterizations}

Surfaces were characterized by means of surface average roughness, water contact angle and diiodomethane con- tact angle (Table 1). Obtained values of roughness can are similar. Only two samples are slightly different: A-green and B-black. In par- ticular A-Green shows a sponge-like surface morphology and a Sa roughness slightly greater.

Table 1: $S_{a}$ roughness. In the bracket the ranking of rough- ness starting from high value.

\begin{tabular}{|c|c|c|c|}
\hline Surface & Mean $[\boldsymbol{\mu m}]$ & RMS $[\boldsymbol{\mu m}]$ & RE [\%] \\
\hline Carbon steel (reference) & 2,23 & 0,056 & 2,49 \\
\hline A-Blue (5) & 2,09 & 0,001 & 0,04 \\
\hline A-Green (1) & 3,25 & 0,106 & 3,26 \\
\hline B-Black (2) & 2,87 & 0,017 & 0,59 \\
\hline B-Green (4) & 2,13 & 0,004 & 0,19 \\
\hline
\end{tabular}

Interfaces interactions between coated surfaces and polar and non-polar liquids were assessed, respectively, by means of water contact angle (WCA) and Diiodomethane contact angle (DCA) measured with sessile drop method. Measured contact angles are in good agreement with liter- ature. No significant deviation from typical values was found for PTFE based coating, and only a small underesti- mate was found for

\section{THF hydrates adhesion tests}

Adhesion tests on THF system were repeated on each surfaces 5 times. The carbon steel case and B samples cases were not reported because not all hydrates was detached from the coating and because of the over-range measured with the instrument. 


\section{Recent Advances in Petrochemical Science}

\section{Methane hydrates adhesion tests}

Adhesion test on methane hydrate, performed in auto- claves with the torque balance, were repeated 3 times for each material.
Total detachment of the hydrate was also verified. Shear stress was calculated by means of eq.1. A comparison of results obtained by the two different methods are reported in Table 2 (Figure 2)

Table 2: Shear stress measured on hydrate THF adhesion test and on methane hydrate adhesion test.

\begin{tabular}{|c|c|c|c|c|c|}
\hline Shear Stress [Kpa] & Carbon Steel & A Green FEP & A Blue PTFE & B Black PTFE & B Green FEP \\
\hline $\begin{array}{c}\text { THF hydrate } \\
\text { detachment }\end{array}$ & 289 & 19 & 97 & $81\left(^{*}\right)$ & $69\left(^{*}\right)$ \\
\hline $\begin{array}{c}\text { High-pressure } \\
\text { apparatus }\end{array}$ & $>130$ & 22 & 18 & 6 \\
\hline
\end{tabular}

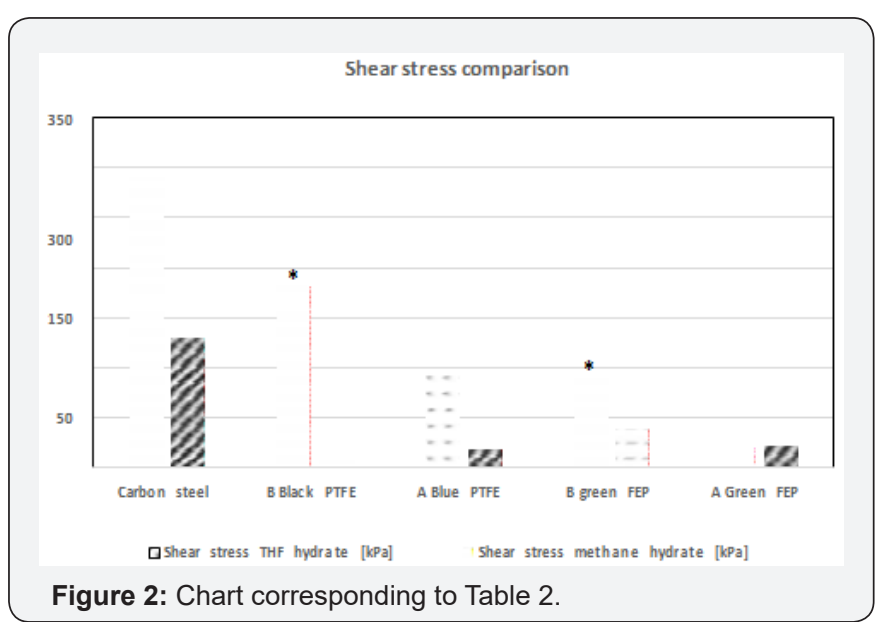

\section{Conclusion}

Tests were performed to investigate the capability of different commercial polymeric coatings to reduce the adhe- sion of methane hydrate on the inner surface of pipelines. In order to reach this goal a new test system was designed and built to measure the adhesion force of a hydrocarbon hydrates at high pressure.

The results were compared with adhesion tests performed on a THF model system, showing that the latter can underestimate the performance of coatings with respect to the results achieved under more representative conditions and also lead to inaccurate rankings.

\section{References}

1. Sloan ED, Carolyn K (2007) Clathrate Hydrates of Natural Gases. In: ( $3^{\text {rd }}$ edn), CRC Press, Taylor \& Francis Group, USA, p. 752.

2. Carroll J (2009) Natural Gas Hydrates: A Guide for Engineers. In: (3 $3^{\text {rd }}$ edn) Gulf Professional Publishing, USA, pp. 288.

3. Smith JD, Meuler AJ, Bralower H, Venkatesan R, Subramanian S, et al (2012) Hydrate-phobic surfaces: fundamental studies in clathrate hydrate adhesion reduction. Phys Chem Chem Phys 14(17): 60136020 .



\begin{tabular}{l} 
Your next submission with Juniper Publishers \\
will reach you the below assets \\
- Quality Editorial service \\
- Swift Peer Review \\
- Reprints availability \\
- E-prints Service \\
- Manuscript Podcast for convenient understanding \\
- Global attainment for your research \\
- Manuscript accessibility in different formats \\
( Pdf, E-pub, Full Text, Audio) \\
- Unceasing customer service \\
Track the below URL for one-step submission \\
https://juniperpublishers.com/online-submission.php \\
\hline
\end{tabular}

